\title{
Pharmacological Models for Short Term Memory Deficiency in Alzheimer's Disease: First Scopolamine Then Diazepam?
}

\section{Eugen Tarnow*}

Data Scientist and Director of Consulting, Avalon Business Systems, 19-03 Maple Avenue, Fair Lawn, NJ 07410, USA

${ }^{*}$ Corresponding author: Eugen Tarnow, Data Scientist and Director of Consulting, Avalon Business Systems, 19-03 Maple Avenue, Fair Lawn, NJ 07410, USA, Tel: 1646825 9080; Fax: (615) 875-0101; E-mail: etarnow@avabiz.com

Received date: June 28, 2017; Accepted date: June 30, 2017; Published date: July 05, 2017

Citation: Tarnow E (2017) Pharmacological Models for Short Term Memory Deficiency in Alzheimer 's Disease: First Scopolamine Then Diazepam?. Dual Diagn Open Acc Vol.2 No.2: 32.

Copyright: (02017 Tarnow E. This is an open-access article distributed under the terms of the Creative Commons Attribution License, which permits unrestricted use, distribution, and reproduction in any medium, provided the original author and source are credited.

\section{Clinical Image}

The signature of a drug or disease on the serial position curve of free recall is the item-by-item difference compared with placebo. Early Alzheimer's disease (average MMSE=26) has one signature, a positive slope, and somewhat later (average MMSE=20) a zero slope (Figure 1). The free recall signatures of scopolamine and diazepam are shown in (Figures 2 and 3), respectively. Scopolamine shows a positive slope, and diazepam, a zero slope. In the limited context of free recall, scopolamine acts as pharmacological model of early Alzheimer's disease and diazepam of later Alzheimer's disease [1-4].

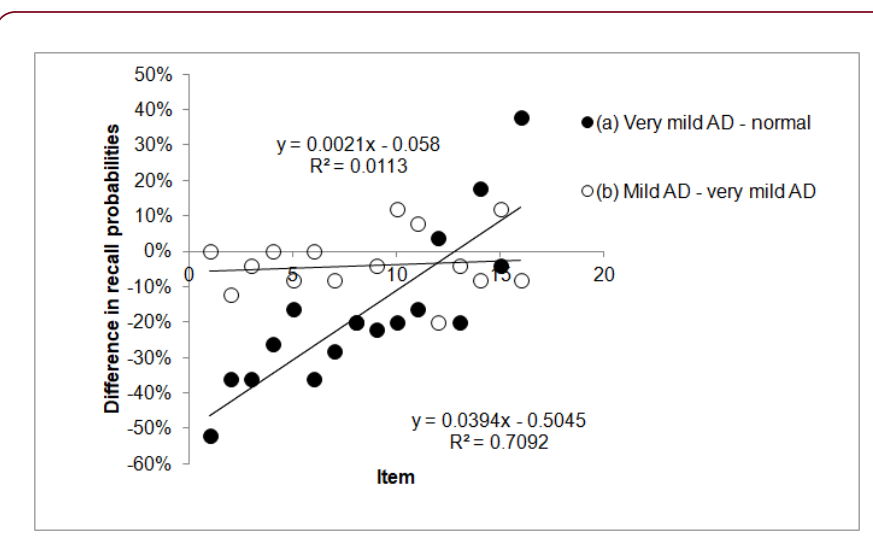

Figure 1: Changes in the free recall serial position curve as Alzheimer's disease progresses from normal to very mild (MMSE<24) and very mild to mild (MMSE $\geq 24)$.

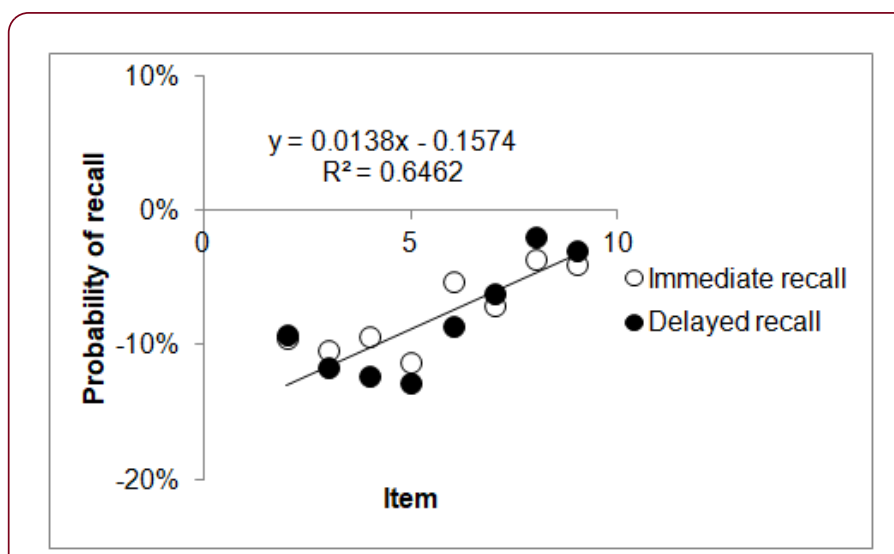

Figure 2: Top panel- Change in serial position curve from scopolamine (intravenous $5.7 \mathrm{Mg} / \mathrm{kg}$ ) in a serial recall experiment (Frith et al. 1984) scored with and without order information. The signature is similar to early AD. Bottom panel: Change in serial position curve from scopolamine (intravenous $0.4 \mathrm{mg}$ ) from Crowe \& Grove-White (1973). The signatures are the same for the two conditions in each experiment. Note the medium R2. 


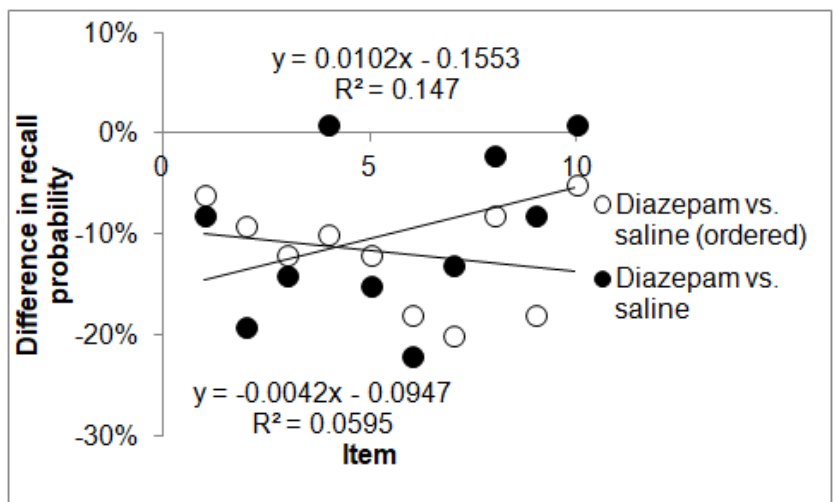

Figure 3: Change in serial position curve from diazepam only (intravenous $5.7 \mathrm{mg} / \mathrm{kg}$ ) in a serial recall experiment (Frith et al. 1984) scored with and without order information. Note the low R2.

\section{Reference:}

1. Bayley PJ, Salmon DP, Bondi MW, Bui BK, Olichney J, et al. (2000) Comparison of the serial position effect in very mild Alzheimer's disease, mild Alzheimer's disease, and amnesia associated with electroconvulsive therapy. J Int Neuropsychol Soc 6: 290-298.

2. Crow TJ, GroveWhite IG (1973) An analysis of the learning deficit following hyoscine administration to man. $\mathrm{Br} \mathrm{J}$ Pharmacol 49: 322-327.

3. Frith CD, Richardson JTE, Samuel M Crow TJ, McKenna PJ (1984) The effects of intravenous diazepam and hyoscine upon human memory. Q J Exp Psychol (Hove) 36: 133-144.

4. Tarnow E (2016) Indirect Evidence: Mild Alzheimer's Disease \& Cannabis Affect The Second State of Free Recall Suggesting Localization in Hippocampal CA1, RUDN. J Psyc Pedag 2: 36-44. 